\title{
Efeito do óleo de Canabidiol (CBD) sobre a acne
}

\author{
Effect of Cannabidiol (CBD) oil on acne \\ Efecto del aceite de Cannabidiol (CBD) en el acné
}

\section{Resumo}

O canabidiol é um canabinóide não psicoativo isolado da Cannabis sativa que, devido às suas alegadas propriedades benéficas e seu potencial terapêutico, está sendo cada vez mais discutido na comunidade científica, à medida que a descriminalização e a legalização desses produtos continuam a se expandir. Tendo em vista o crescente interesse, ainda que a legislação sobre este tema no Brasil seja limitada, o objetivo principal deste estudo foi investigar a aplicação do canabidiol (CBD) na influência dos aspectos relacionados às propriedades anti-inflamatórias e antimicrobiana sobre a acne. Internacionalmente, protocolos para o uso do produto já foram estabelecidos. Nesse contexto, foi realizada uma revisão da literatura atual para evidenciar as aplicações de canabidiol para a pele, a partir de estudos químicos e farmacológicos, com diversos alvos moleculares, incluindo receptores de canabinoides e do sistema endocanabinoide, com os quais eles interagem. Foi identificado que os produtos canabinoides apresentam potencial para tratar uma variedade de doenças de pele, incluindo acne. No entanto, a maioria dos dados disponíveis sobre esses compostos são estudos pré-clínicos, que necessitam de estudos controlados de alta qualidade para avaliar seus efeitos de forma complementar. Este artigo fornece uma atualização sobre os avanços na pesquisa de CBD e as áreas potenciais de exploração futura.

Palavras-chave: Canabidiol; Pele; Acne; Sistema endocanabinoide.

\begin{abstract}
O Cannabidiol is a non-psychoactive cannabinoid isolated from Cannabis sativa which, due to its alleged beneficial properties and therapeutic potential, and a topic increasingly discussed as decriminalization and legalization of these products continue to expand, has recently raised considerable interest attention of the scientific community. And with little evidence in the literature, the main objective of this study was to investigate the administration of CBD, with a particular focus on the influence of aspects related to anti-inflammatory, antimicrobial properties on acne. However, the current role of CBD in the treatment of dermatological conditions remains to be defined. We performed a review of the current literature to determine the skin applications of cannabinoids. After performing our analysis, we found that cannabinoid products have the potential to treat a variety of skin conditions, including acne. However, most of the data available on these compounds are preclinical and there is a corresponding lack of high-quality controlled studies evaluating their effects. With the chemistry and pharmacology of CBD, and with various molecular targets, including cannabinoid receptors and the endocannabinoid system with which they eventually interact, have been studied extensively. This article provides an update on advances in CBD research to date and potential areas for future exploration.
\end{abstract}

Keywords: Cannabidiol; Skin; Acne; Endocannabinoid system.

\section{Resumen}

El cannabidiol es un cannabinoide no psicoactivo aislado de Cannabis sativa que, debido a sus supuestas propiedades beneficiosas y potencial terapéutico, y un tema cada vez más discutido a medida que la despenalización y legalización 
de estos productos continúan expandiéndose, recientemente ha despertado un interés considerable en la comunidad científica. Y con poca evidencia en la literatura, el objetivo principal de este estudio fue investigar la administración de $\mathrm{CBD}$, con un enfoque particular en la influencia de aspectos relacionados con las propiedades antiinflamatorias y antimicrobianas sobre el acné. Sin embargo, queda por definir el papel actual del CBD en el tratamiento de afecciones dermatológicas. Realizamos una revisión de la literatura actual para determinar las aplicaciones cutáneas de los cannabinoides. Después de realizar nuestro análisis, descubrimos que los productos cannabinoides tienen el potencial de tratar una variedad de afecciones de la piel, como el acné. Sin embargo, la mayoría de los datos disponibles sobre estos compuestos son preclínicos y existe una falta correspondiente de estudios controlados de alta calidad que evalúen sus efectos. Se ha estudiado ampliamente la química y la farmacología del CBD, y con varios objetivos moleculares, incluidos los receptores cannabinoides y el sistema endocannabinoide con el que eventualmente interactúan. Este artículo proporciona una actualización sobre los avances en la investigación del CBD hasta la fecha y las áreas potenciales para futuras exploraciones.

Palabras clave: Cannabidiol; Piel; Acné; Sistema endocannabinoide.

\section{Introdução}

A pele humana é habitada por uma grande variedade de microrganismos, incluindo bactérias, fungos e vírus. O equilíbrio entre esses microrganismos é essencial para imunidade local e para o bom funcionamento da barreira da pele. Os desequilíbrios desse sistema estão associados a doenças dermatológicas, como acne, dermatite atópica, psoríase e rosácea. (Castillo et al., 2019).

Pesquisas relacionadas ao tema acne estão à procura de ativos dermatológicos que possam atuar nas múltiplas etapas que envolvem a sua patogenesia, tais como superprodução de sebo, proliferação de sebócitos e inflamação, sem que tenha qualquer efeito colateral no tratamento. (Oláh et al., 2014).

A descoberta de novas propriedades biológicas e farmacológicas dos canabinóides tópicos propõem diversas indicações terapêuticas relacionadas à pele, baseando-se na capacidade de modular a resposta inflamatória e mostrando-se eficaz no tratamento de várias condições dermatológicas incluindo a acne. (Casiraghi et al., 2020).

Uma vez que os canabinoides tópicos são apresentados pela indústria como possibilidade de tratamento para certas doenças dermatológicas, o uso da Cannabis sativa vem se tornando cada vez mais presente nos Estados Unidos, países europeus, Austrália e Canadá, onde médicos apresentam prescrições com produtos derivados da Cannabis. No entanto, ainda há desconhecimento e até mesmo desconforto para a prescrição deste ativo que durante anos esteve relacionado somente às substâncias psicoativas. (Hashim et al., 2017; Dhadwal, \& Kirchhof, 2018; Lim \& Kirchhof, 2019). No Brasil, a ANVISA, agência regulatória de medicamentos e cosméticos do Brasil, vem acompanhando o desdobramento acadêmico e comercial do tema através de uma legislação que seja pertinente ao tema. (Brasil, 2019) Estudos identificam que o fitocanabinoide CBD pode ser um potente agente antiacne, seguro ao uso humano, uma vez que o CBD é considerado um agente não psicoativo e antagonista dos receptores CB1 e CB2, mesmo em pequenas concentrações. (Souza et al., 2021).

Atualmente o padrão ouro de tratamento para acne severa Grau III e IV é isotretinoína, medicamento que pode apresentar vários efeitos colaterais. Além disso, muitos países já desenvolveram protocolos para a prática clínica sem quaisquer efeitos colaterais significativos, para outras patologias, o que pode ser promissor para abertura de pesquisas em inúmeras áreas. (Oláh et al., 2014).

Em consideração ao interesse científico e comercial, estão sendo desenvolvidas formulações tópicas de CBD tais como o óleo, cremes e géis para serem comercializados como medicamento ou cosméticos. Em relação as demais doenças de pele, produtos com propriedades antisseborreicas, antienvelhecimento, anti-inflamatória e antioxidante foram lançados no mercado. (Casiraghi et al., 2020).

Algumas empresas estão desenvolvendo produtos à base de $\mathrm{CBD}$, como por exemplo, géis com permeação transdérmica em ensaios de fase II e até em estudos clínicos indicados para acne, psoríase e dermatite. (Millar et al., 2020).

Nessa perspectiva, a revisão bibliográfica aqui apresentada aborda trabalhos científicos publicados sobre os aspectos da 
acne, benefícios do uso do óleo CBD, com foco ação anti-inflamatória e antioxidante na pele, assim como seus receptores endocanabinoides CB1 e CB2, que influenciam consideravelmente a regulação neuroimunoendócrina do funcionamento da pele, conservando sua homeostase.

\section{Metodologia}

Trata-se de uma revisão bibliográfica integrativa baseado na metodologia proposta por Souza e colaboradores (2010) através de estudos científicos que investigam os efeitos antimicrobianos e anti-inflamatórios da Cannabis sativa com foco no potencial do óleo de CBD sobre a Cutibacterium acnes através do sistema endocanabinoide (SEC), seus receptores CB1 e CB2 e seus ligantes endógenos anandamida (AEA) e 2-araquidonoilglicerol (2-AG). As pesquisas foram realizadas nas bases de dados PubMed, MDPI, ScienceDirect e Google Acadêmico com artigos, teses e dissertações relacionadas aos canabinoides nos últimos anos, utilizando as palavras-chaves: Cannabis sativa, canabidiol, sistema endocanabinoide, pele e acne. Os parâmetros utilizados foram: identificação do tema; definição dos critérios de inclusão e exclusão; categorização de artigos; análise e interpretação dos dados encontrados e realização da conclusão. (Figura 1).

Foram selecionados através dos critérios de inclusão e exclusão, um total de 47 artigos indexados em periódicos classificados pelo Qualis Cape como A e B, com o objetivo de compreender quais são os principais efeitos antimicrobianos e anti-inflamatórios da Cannabis sativa no tratamento da acne.

Figura 1. Processo de seleção dos artigos de referência.

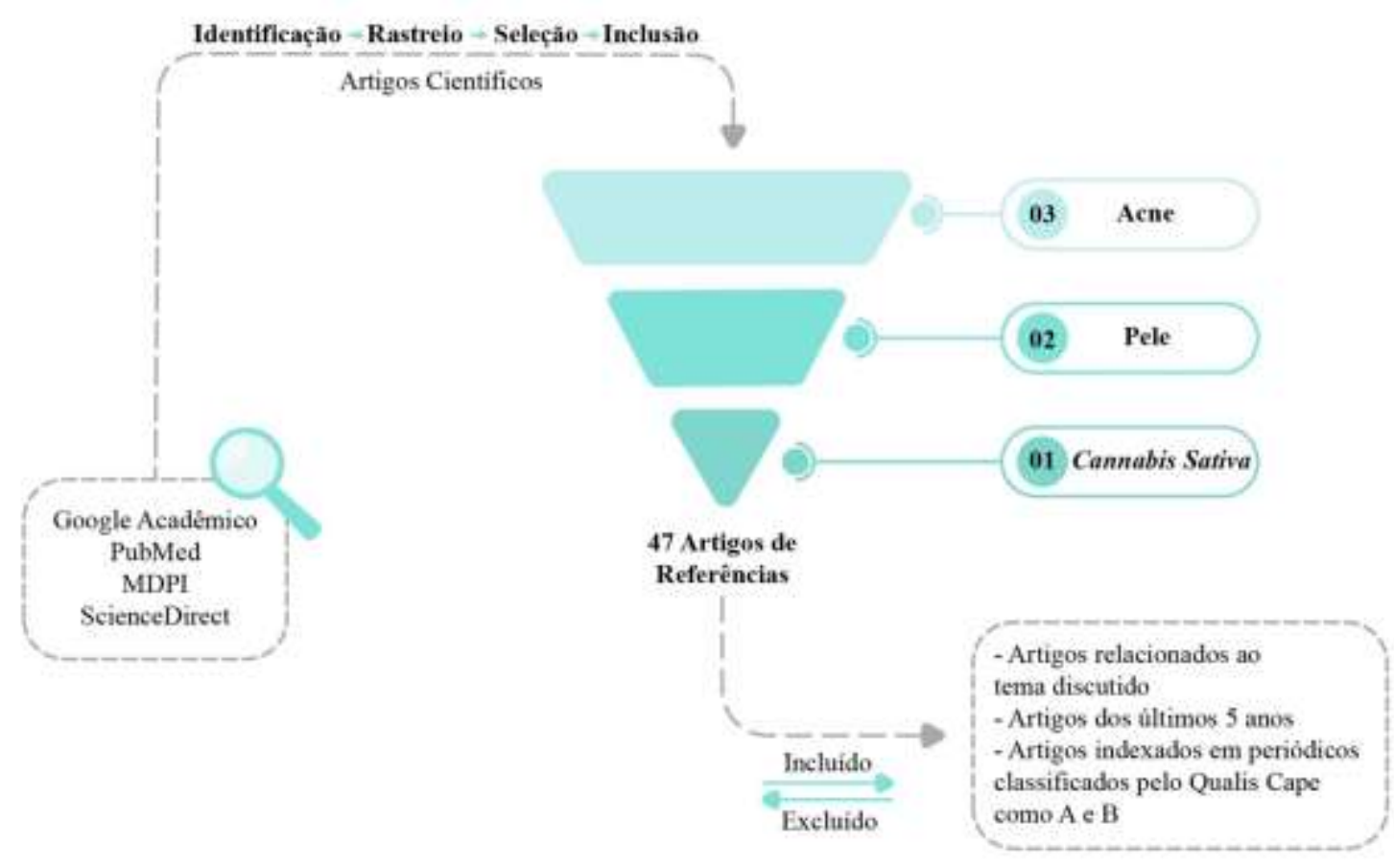

Fonte: Autores.

\section{Pele}

A pele é um sistema epitelial que tem como principal função o revestimento externo do corpo, a fim de isolar as estruturas internas do ambiente externo. Trata-se do órgão mais extenso do ser humano, com aproximadamente 1,8m2. O padrão histológico da pele é constituído por duas camadas: epiderme e derme, sendo a epiderme a camada fina contendo a cerca de 0,1 
mm de espessura, situando-se agrupada a segunda camada, denominada de derme que se apresenta mais espessa. (Chambers, Emma S, 2020).

A pele é uma barreira protetora contra as agressões ambientais que podem gerar espécies reativas de oxigênio. O estresse oxidativo induz ao dano celular e a inflamação crônica, se não for controlado, podendo causar doenças e o envelhecimento da pele. Os queratinócitos são os principais tipos de células da epiderme e são particularmente sensíveis ao estresse ambiental. (Baswan et al., 2020).

\subsection{Epiderme}

A epiderme é a camada mais externa da pele, sendo a principal barreira protetora que impede as interferências do ambiente externo e a saída do conteúdo interno, principalmente água, nutrientes e eletrólitos. Os queratinócitos são as principais células epidérmicas encontradas na epiderme, correspondendo a $90 \%$ de sua composição, além da capacidade de produzir queratina, responsável por gerar os corneócitos. São encontrados também os melanócitos, as células de Merkel e as células de Langerhans, que são transpassadas por estruturas dos anexos que são invaginados na derme como as glândulas sudoríparas e os folículos pilossebáceos. (Gravitz, 2018).

Existem quatro camadas na epiderme, sendo elas: basal, espinhosa, granulosa e córnea. Manifesta, ainda, a camada lúcida, que está presente nos locais onde a pele é mais fina, tais como pés, joelhos e cotovelos. Cada uma destas camadas dispõe de caraterísticas bem diferenciadas e que influenciam no biotipo cutâneo, estando presente de maneira diferenciada nas diversas partes do corpo humano. (Bollag, Wendy Bollinger, 2020).

Figura 2. Exemplificação das camadas que compõem a epiderme.

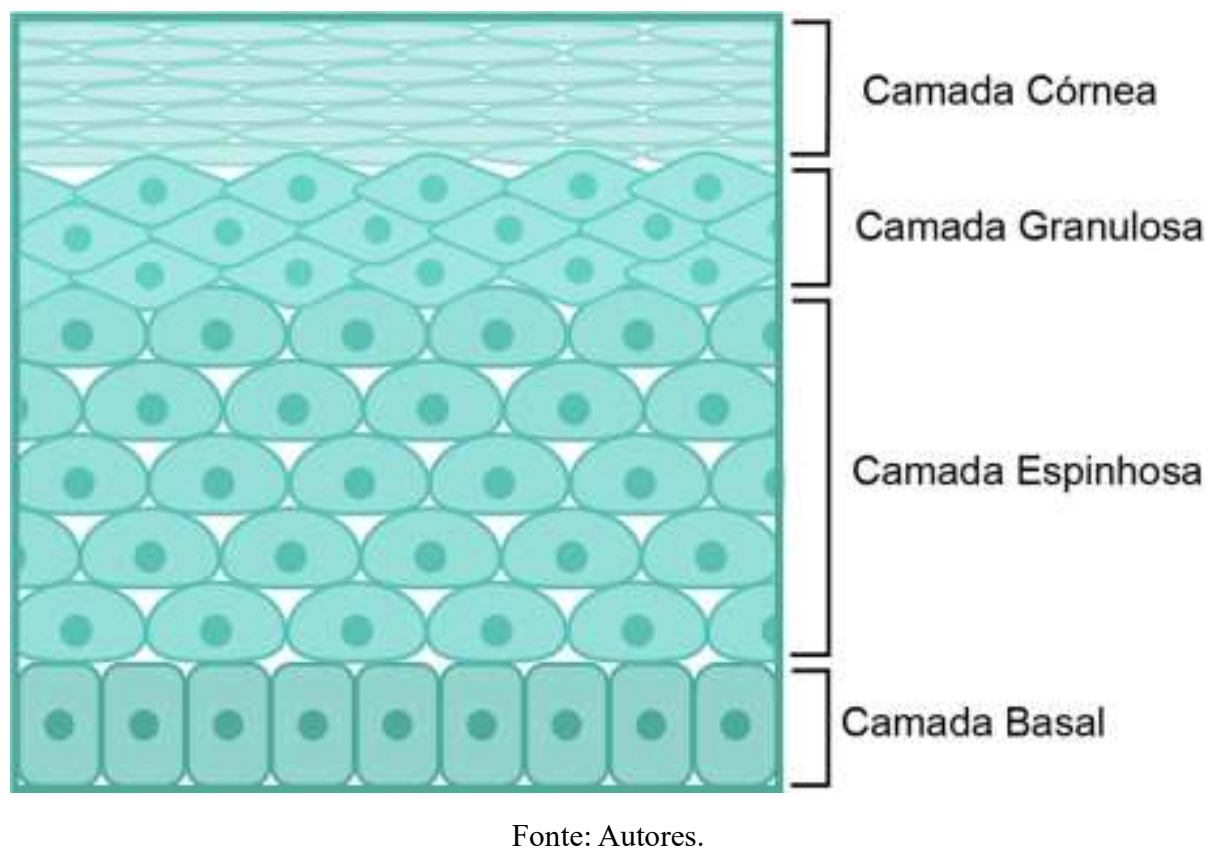

Sendo a epiderme dividida em estratos, a camada basal é a mais interna, rica em queratinócitos, onde ocorre a produção de células tronco que se dividem constantemente em mitose, transformando seu formato de cubonais a colunares. Esta camada promove renovação celular. (Yousef et al. 2020).

A próxima camada chama-se espinhosa. Apresenta células poliédricas e são ligadas por desmossomos que, em doenças como a psoríase e dermatite, tem o mecanismo de esfoliação acelerado pela quebra dos desmossomos. (Hargis, \& Myers, 2017). 
Já a camada granulosa é composta por 3 a 5 camadas de células com grânulos de cerato-hialina, que possui percursores de queratina, e os grânulos lamelares, que possui glicolipídios excretados para a superfície. (Yousef et al. 2020).

A camada córnea, camada mais superficial é composta de 10 a 30 camadas celulares. Formada por camadas de corneócitos que são enucleados, rico em proteínas unidas por lipídeos. A pele negra e a pele oleosa possuem mais camadas córneas, promovendo uma proteção extra ao tecido. Executa um papel importante mantendo a retenção de água, evitando o ressecamento da pele. (Osseiran et al. 2018).

Os receptores canabinoides CB1 e CB2 estão situados nos queratinócitos. Os canabinoides inibem a proliferação e a diferenciação dos queratinócitos da epiderme e conduzem a apoptose, eles influenciam consideravelmente a regulação neuroimunoendócrina do funcionamento da pele e conservam sua homeostase, junto com o sistema endocanabinoide que colabora com a coordenação da reposta inflamatória da pele. (Graczyk et al. 2021).

\subsection{Derme}

A derme é dividida em duas camadas, papilar e reticular. A derme papilar está localizada na parte superior da derme, sendo constituída por terminações nervosas e vasos microvasculares, que são necessários para nutrição e inervação da pele. Apresenta maior densidade em relação a reticular e uma quantidade maior de proteoglicanos. A derme reticular localiza-se abaixo da derme papilar. A matriz extracelular tem uma estrutura composta por feixes de fibras de colágeno junto com os fios de elastina, na qual se forma uma estrutura forte que ao longo dos anos se deforma. (Rippa et al. 2019).

As glândulas sebáceas são compostas por sebócitos diferenciados que liberam óleos na superfície da pele, contribuindo com até $90 \%$ dos lipídios na derme. Acredita-se que esses lipídios, que são secretados como parte de uma mistura complexa conhecida como sebo, desempenhem inúmeras funções, incluindo hidratação da pele, repulsão de água, termorregulação, bem como funções antioxidantes e antimicrobiana, e quando em excesso estão associadas a uma variedade de doenças de pele, inclusive a acne. (Veniaminova et al., 2019).

A derme é um local importante para o processamento e modulação de andrógenos. As enzimas necessárias para transformar o colesterol em esteroides ou precursores adrenais, como a deidroepiandrosterona, são encontradas na pele. A glândula sebácea também pode inativar os andrógenos por meio da hidroxiesteroide desidrogenase, uma enzima presente logo nas 16 semanas de vida fetal. A isoforma tipo 1 da 5 -alfa-redutase, que serve para converter a testosterona em sua forma mais potente, também é abundantemente produzida nas glândulas sebáceas, especialmente nas encontradas na face e couro cabeludo. (Hoover; Krishnamurthy, 2020).

\section{Cannabis sativa}

A Cannabis é uma planta originária da China pertencente à família Cannabaceae, que apresenta três espécies, a sativa, indica e ruderalis. Suas flores são femininas e masculinas que florescem em plantas divergentes, configurando uma espécie dioica, sendo que as hermafroditas são raramente encontradas. Trata-se de uma angiosperma que apresenta folhas finas, pontiagudas e serrilhadas. (Lewis et al., 2017; Souza et al., 2021)

A Cannabis sativa é dividida em duas categorias de subespécies, baseada na concentração de moléculas psicoativas de tetrahidrocanabidiol (THC). A categoria medicamentosa é reconhecida por conter até $20 \%$ de THC, e a não medicamentosa, chamada cânhamo, possui nível de THC abaixo de $0,2 \%$. Essa substância foi reconhecida para o uso farmacêutico depois do século XIX, onde descobriu-se a efetividade dos canabinoides. (Isidore et al., 2021).

Apresentando uma grande diversidade de metabólitos secundários em sua composição, ela é considerada uma planta quimicamente complexa, contendo aproximadamente 550 compostos, sendo 113 fitocanabinoides e 120 terpenos, destacando-se 
os terpenos, flavonoides, alcaloides, canabinoides, ácidos graxos, fenóis (ex.: THC), óleos vegetais, tocoferol, carotenos e outros compostos fenólicos. (Aizpurua-Olaizola et al., 2016).

Figura 3. A. Representação do cânhamo, características apresentadas para ser considerado cânhamo, plantas com nível de <0,2\% THC, caule fino e alta estrutura. B. Cannabis sativa.

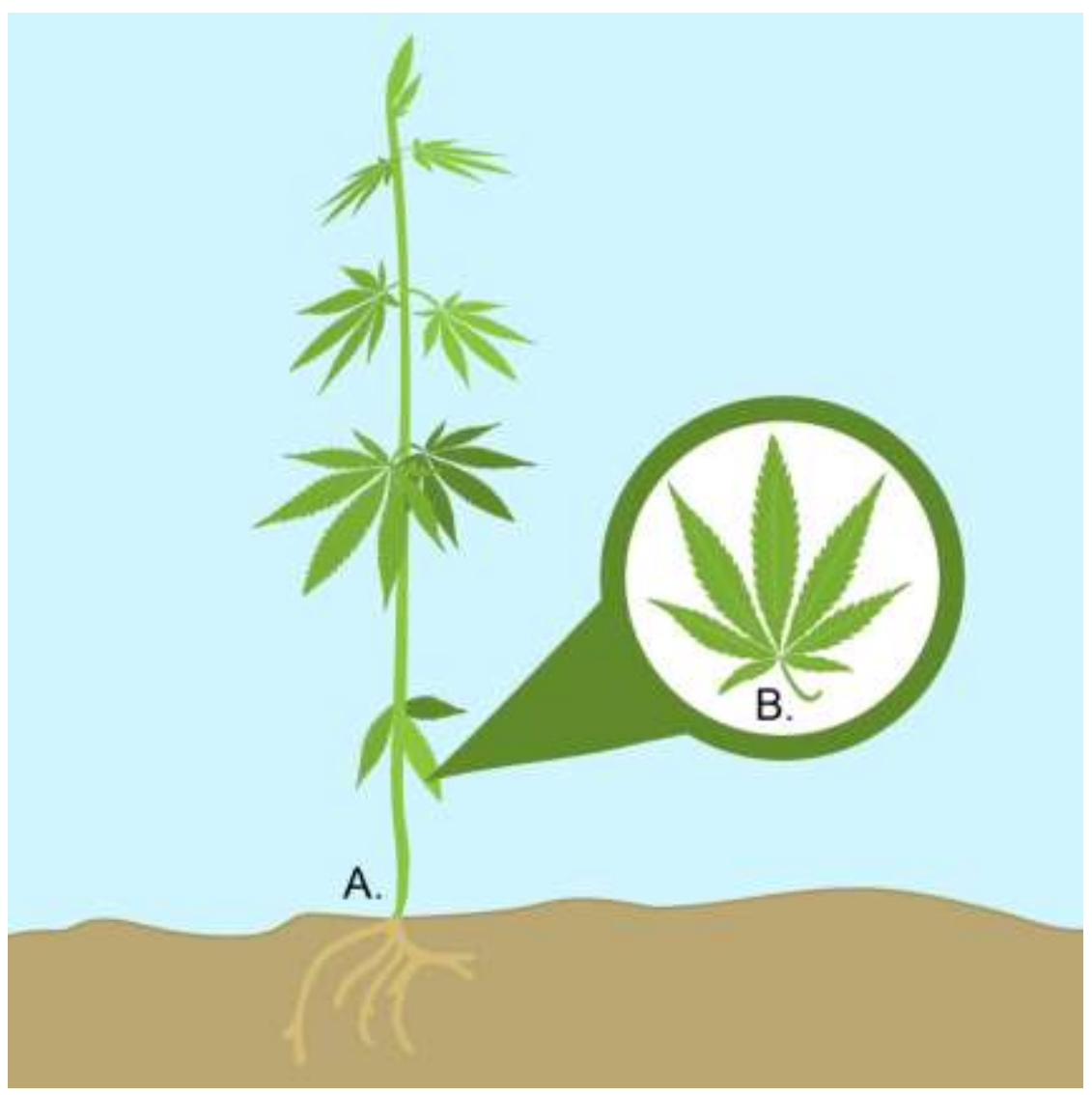

Fonte: Autores.

\subsection{Tipos de canabinoides}

Os canabinoides podem ser divididos em três categorias gerais: endocanabinoides são os compostos canabinoides biossintetizados no corpo humano; os fitocanabinoides são os canabinoides obtidos de plantas; enquanto os canabinoides sintéticos são gerados sinteticamente usando vários processos químicos, como por exemplo Dronabinol e Nabilona (Figura 4). Os fitocanabinoides são encontrados em abundância nos tricomas produtores de resina da canabis, órgãos reguladores que normalmente os segmentam em dois quimiotipos distintos. O cânhamo é o quimiotipo com uma quantidade mínima de tetrahidrocanabinol (THC) e níveis mais altos de CBD, já o quimiotipo da canabis contém altos níveis de THC. (Baswan et al., 2020).

Canabinoides são isolados de folhas, flores, caules, raízes e sementes, mas a principal fonte de fitocanabinoides são os tricomas de flores femininas não fertilizadas, que secretam uma resina carregada de fitocanabinoides. (Souza et al., 2021). 
Figura 4. Classificação dos canabinoides.

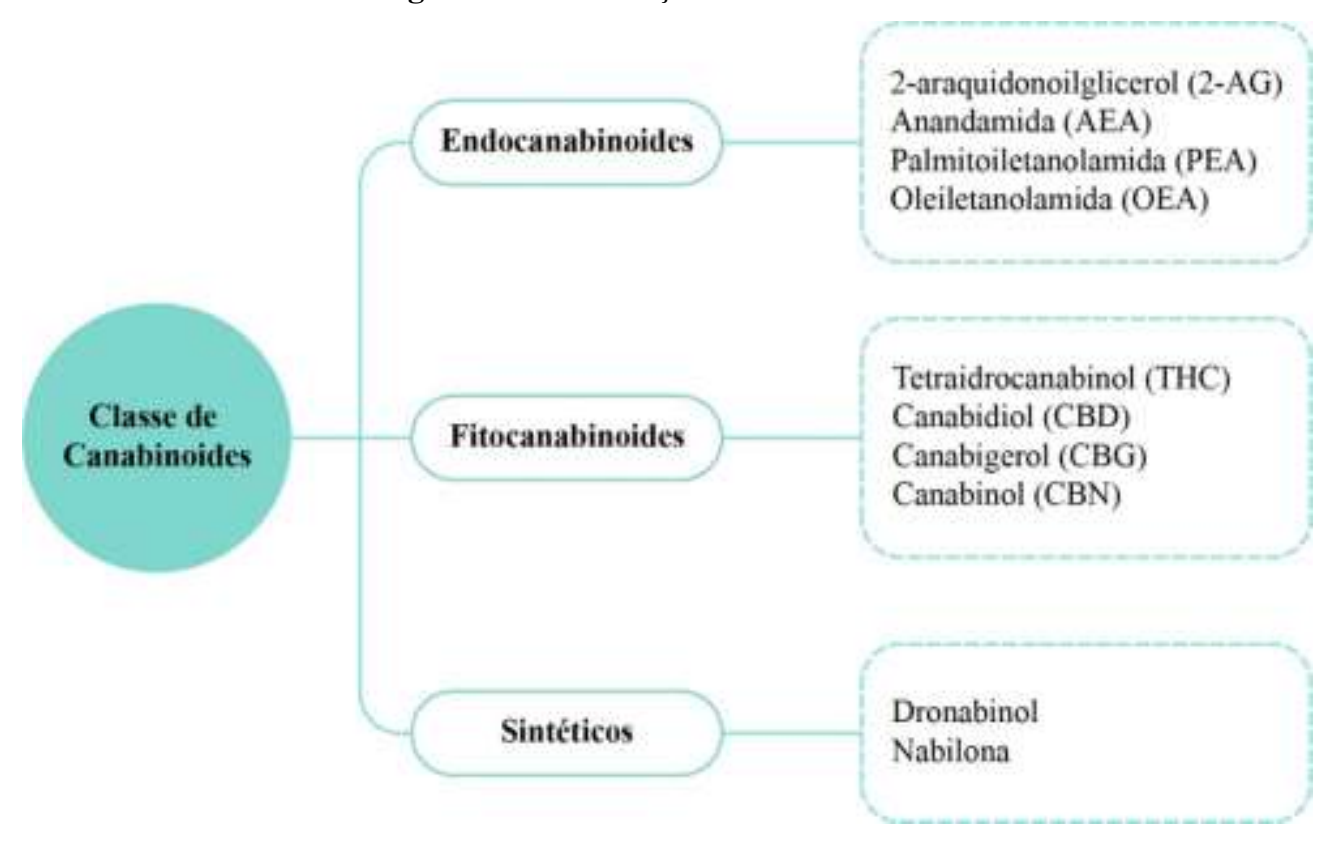

Fonte: Autores.

\subsection{Canabidiol}

Sendo catalogada em 1963, a terminologia atual preferida da IUPAC é 2 - [(1R, 6R) -3-metil-6-prop-1-en-2-ilciclohex2-en-1-il] -5-pentilbenzeno-1,3-diol de ocorrência natural. O canabidiol (CBD) é um composto de terpenofenol contendo vinte e um átomos de carbono, com a fórmula $\mathrm{C}_{21} \mathrm{H}_{30} \mathrm{O}_{2}$ e um peso molecular de 314,464 g / mol. A estrutura química do canabidiol é 2- [1R-3-metil-6R- (1-metiletenil) -2-ciclohexen-1-il]-5-pentil-1,3-benzenodiol, o CBD contém um anel de ciclohexeno (A), um anel fenólico (B) e uma cadeia lateral pentila, o anel terpênico (A) e o anel aromático (B) estão localizados em planos quase perpendiculares entre si (Figura 5). Há três homólogos de cadeia lateral de CBD conhecidos, que são metil, n-propil e o n-butil. (Atalay et al., 2020).

Figura 5. Estrutura química do CBD.



Fonte: Autores.

O canabidiol (CBD) é o fitocanabinoide não psicotrópico bem estudado e manifesta múltiplas atividades, incluindo efeitos antioxidantes e anti-inflamatórios. Com base nessas propriedades, o CBD tem uma gama de utilidade terapêutica em várias condições, incluindo doenças na pele. (Casares et al., 2020).

\subsection{Sistema Endocanabinoide e seus receptores}

Estudos evidenciaram que o corpo humano exibe um sistema endocabinoide (SEC) que pode se ligar e reconhecer especificamente compostos fenólicos terpênicos, como os da Cannabis, conhecidos como fitocanabinoides. Esse sistema possui 
receptor ligantes endógenos, endocanabinoides, e as enzimas envolvidas na síntese e degradação dessas moléculas, que juntas constituem o SEC, uma complexa rede de sinalização intercelular que participa de várias regulações fisiológicas importantes. (Oláh et al., 2016).

A existência do SEC e de ligantes endógenos foi relatada pela primeira vez em 1988 por Devane, quando demonstrou que o glicerol $N$-araquidonoil etanolamina (2-AG), Anandamida (AEA), derivados do ácido araquidônico (Figura 6), interagia com o receptor canabinoide cerebral. A detecção de vários endocanabinoides também foi relatada no corpo humano, incluindo os órgãos periféricos como a pele. Dentre todos os endocanabinoides presentes na pele, AEA, 2-AG, são os mais estudados (Figura 7). Eles também foram detectados e quantificados na faixa fentomolar em queratinócitos e células de fibroblastos. (Baswan et al., 2020; Tallima \& El Ridi, 2018).

Com administração de CBD na de pele humana, houve a inibição das ações lipogênicas de alguns compostos, sendo eles o ácido araquidônico e uma combinação de ácido linoléico e testosterona, e com isso suprimiu a proliferação de sebócitos. (Oláh et al., 2014).

Figura 6. Estrutura química do Ácido Araquidônico.



Fonte: Autores.

Figura 7. Estrutura química da Anandamida e do 2-Araquidonilglicerol.
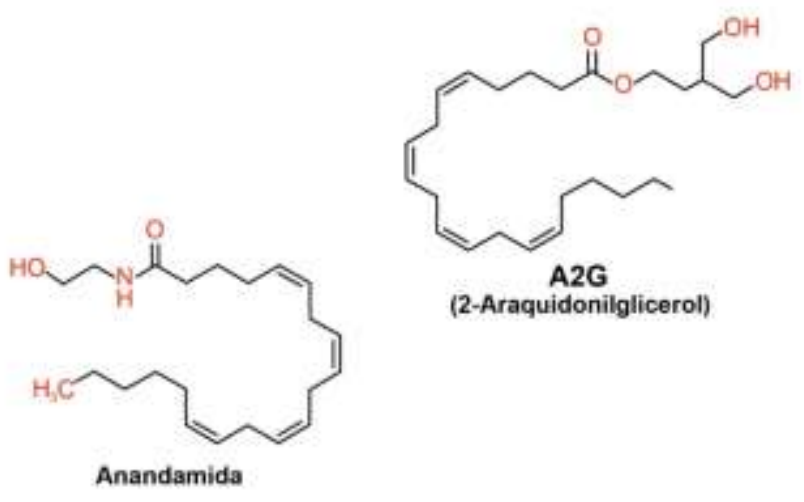

Fonte: Autores.

A pele vai muito além do que um efetor do SEC, dispondo de receptores e sinalizadores de canabinoides, afetando a homeostase das células e dos apêndices cutâneos (Figura 8). Os fatores que influenciam o aparecimento da acne é a hiperprodução 
de sebo. O SEC, além do ajuste da homeostase, atua na lipogênese onde o CBD promove a liberação da AEA. Dessa forma, inibe a produção de ácidos graxos e monoglicerol lipase, estimulando a AEA à produção lipídica em sebócitos humanos em baixas concentrações, porém induz a apoptose em altas concentrações. (Baswan et al., 2020; Correia-Sá et al., 2020; Lowe, et al., 2021).

Figura 8. Representação do SEC em células da pele humana.

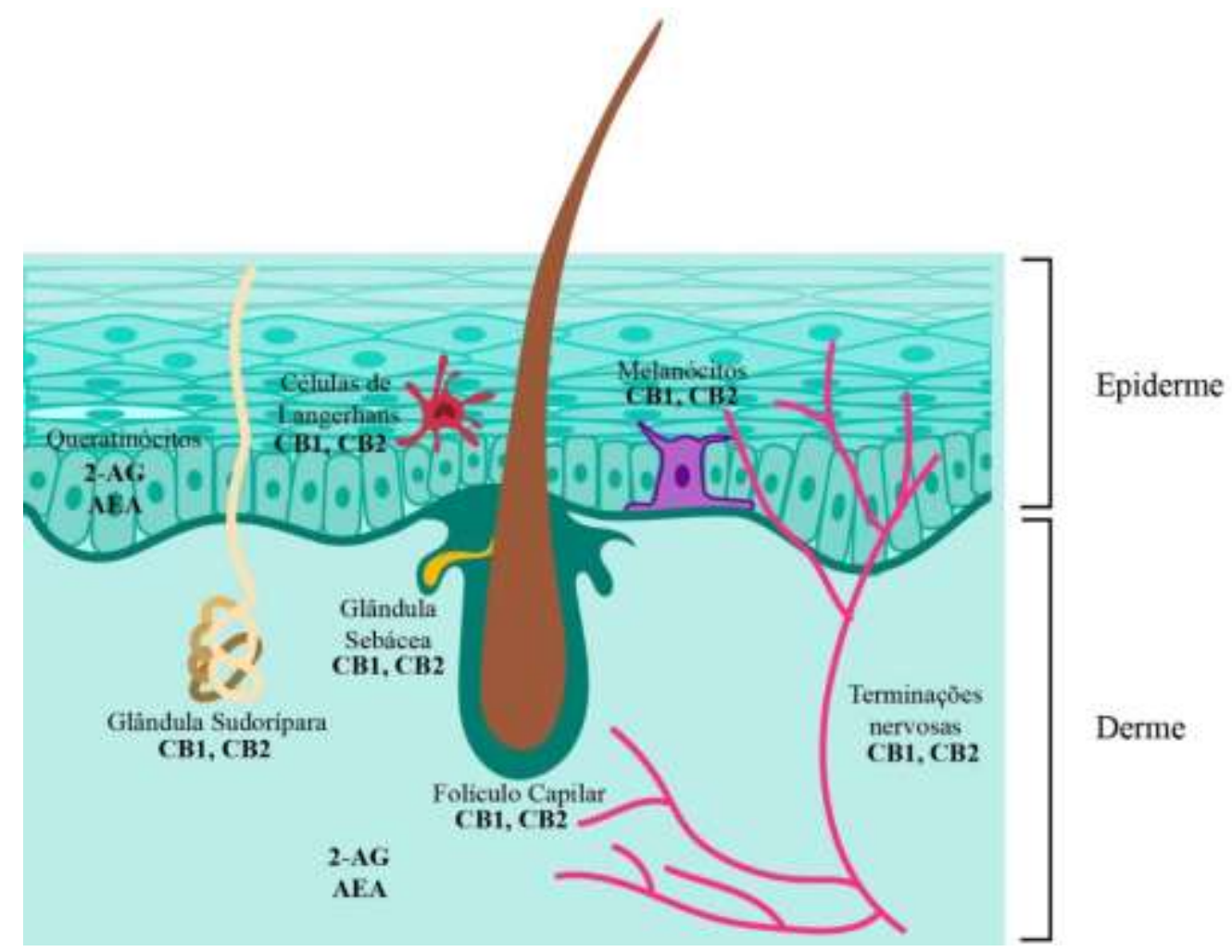

Fonte: Adaptado de Baswan et al. (2020).

Pesquisas indicam que os receptores CB1 e CB2 também são encontrados nos queratinócitos epidérmicos, fibras nervosas cutâneas, células dérmicas, melanócitos, glândulas sudoríparas écrinas e folículos pilosos. (Tabela 1) (Baswan et al., 2020).

Tabela 1. Comparação dos canabinoides CB1 e CB2 sobre sua localização e local de atuação.

\begin{tabular}{|c|c|c|c|}
\hline Referẻncias e ano & Agente de tratamento & Modo de açâo & Resultados \\
\hline $\begin{array}{l}\text { (Chiurchiù, V. et al., } \\
2016 \text { ) } \\
\text { (Nam, G, et al. 2016) }\end{array}$ & Receptor CB1 & $\begin{array}{l}\text { Ativação de } \\
\text { mastócitos }\end{array}$ & $\begin{array}{c}\text { Efeito anti-inflamatório } \\
\text { podendo regular as } \\
\text { doenças inflamatórias } \\
\text { dependentes de } \\
\text { células } \mathrm{T} \text { da pele }\end{array}$ \\
\hline $\begin{array}{l}\text { Ahmed, W., \& Katz, } \\
\text { S., 2016) } \\
\text { (Du, Y, et al., 2018) } \\
\text { (Turcotte, C et al., } \\
2016 \text { ) }\end{array}$ & Receptor CB2 & $\begin{array}{c}\text { Linfócitos B e T, } \\
\text { células NK, monócitos, } \\
\text { neutrófilos e } \\
\text { leucócitos CD8 e CD4 }\end{array}$ & Resposta inflamatória \\
\hline
\end{tabular}


O CB1 é encontrado na membrana plasmática de neurônios localizados em várias estruturas do sistema nervoso central e periférico, mais abundantemente em direção aos terminais sinápticos. A localização pré-sináptica está relacionada ao papel dos canabinoides na modulação da neurotransmissão, explicando um dos efeitos mais comumente conhecidos da ansiólise, que é realizado por diminuições mediadas por CB1 da liberação de ácido $\gamma$-aminobutírico e colecistocinina. CB1 foi identificado em vários tecidos fora do sistema nervoso, como a pele, o trato gastrointestinal, o fígado, o sistema músculo-esquelético e várias células imunológicas. (Figura 9) (Scheau et al., 2020).

Figura 9. Principais áreas de distribuição dos canabinoides no corpo humano.

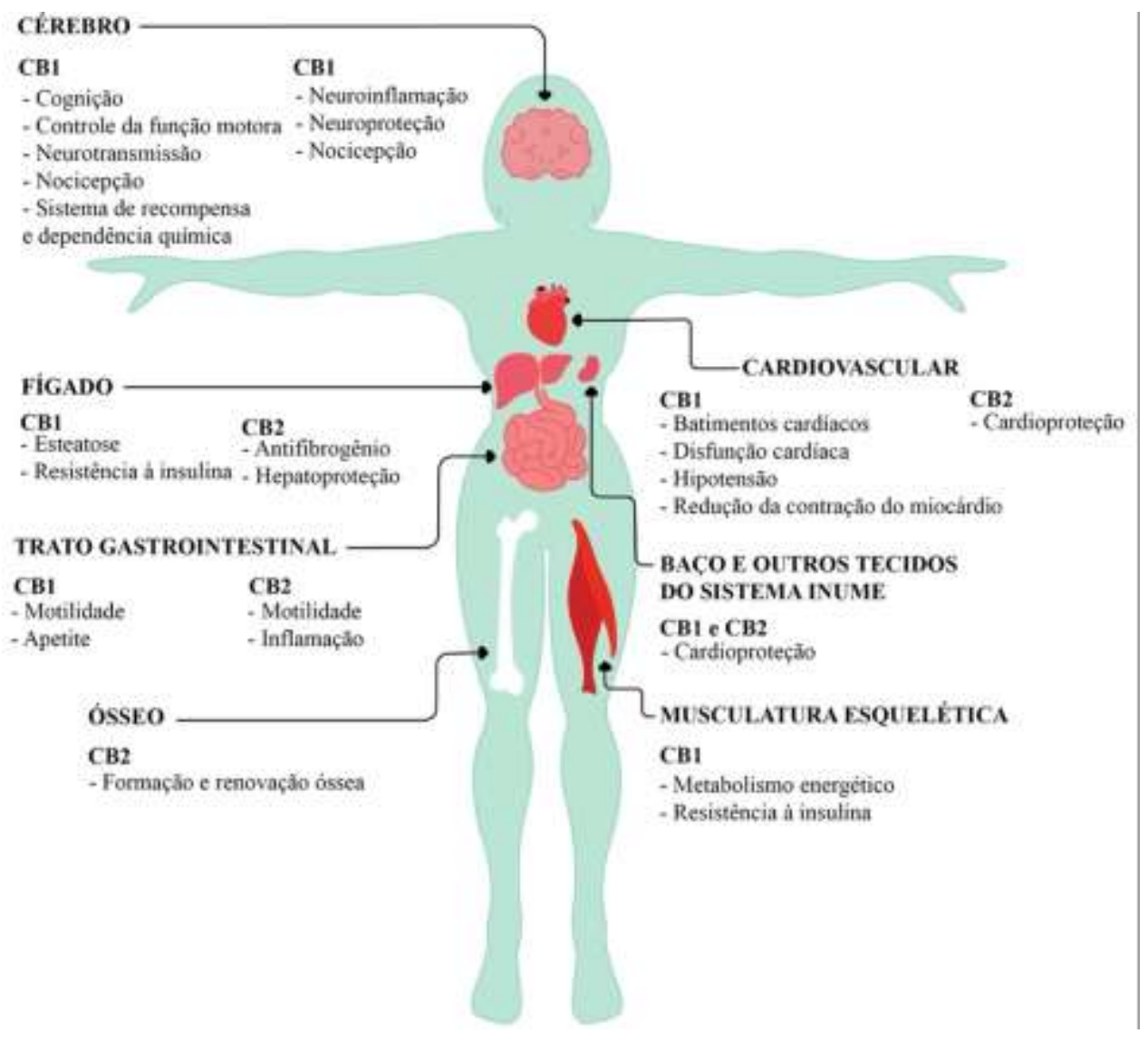

Fonte: Adaptado de An et al. (2020).

Foi demonstrado que o CBD modula a atividade do SEC aumentando os níveis de AEA, que pode afetar a sinalização dos canabinoides, incluindo sua interação nos receptores. Portanto, acredita-se que a atividade antioxidante mais importante do CBD esteja associada ao seu efeito sobre os receptores. Dependendo da concentração pode ativar, antagonizar ou inibir os receptores canabinoides CB1 e CB2. (Atalay et al., 2020; Kupczyk et al., 2009).

\subsection{Ações anti-inflamatória e antioxidante do CBD}

O CBD possui um amplo espectro de atividade biológica, incluindo atividade antioxidante e anti-inflamatória, razão pela qual auxilia na prevenção e tratamento de doenças, cujo desenvolvimento está associado ao desequilíbrio redox e inflamação. A propriedade antioxidante do CBD, assim como em outros agentes antioxidantes está relacionada a sua capacidade em interromper a cascata de reações que ocorrem a partir de formação de radicais livres gerados por espécies reativas de oxigênio, capturando ou transformando-os em formas menos ativas, essas reações dão origem a diversas estruturas de ressonância nas 
quais elétrons desemparelhados são encontrados principalmente em estruturas fenólicas, sugerindo que os grupos hidroxila do anel fenol são os principais responsáveis por estabiliza-los. (Atalay et al., 2020).

O CBD, em baixas doses, resulta em efeitos fisiológicos que promovem a saúde, com ação antioxidante, antiinflamatória e neuroprotetora, mais eficaz que as vitaminas C para a pele. (Iffland; Grotenhermen, 2017).

A literatura apresenta estudos in vivo e in vitro na investigação da absorção do CBD sobre a pele humana. Com o intuito de obter o alvo terapêutico, a molécula tem que permear no estrato córneo e disseminar no decorrer das camadas da epiderme (Casiraghi et al., 2020). Usando queratinócitos humanos, pesquisadores mostraram que o CBD foi capaz de penetrar nas células e equilibrar a resposta ao estresse oxidativo resultante da irradiação UVB e do peróxido de hidrogênio. Foi demonstrado que o CBD tem um efeito protetor contra a redução induzida por peróxido de ácidos graxos poli-insaturados na membrana celular, ajudando a proteger a integridade da membrana. (Baswan et al., 2020).

O CBD atua sinergicamente com a bacitracina contra Staphylococcus aureus e outras bactérias Gram-positivas, despertando interesse para o tratamento de infecções cutâneas pela sua atividade antimicrobiana e anti-inflamatória. (Casiraghi et al., 2020).

\section{Acne}

A acne é uma doença multifatorial, sendo que o aumento da produção de sebo por estimulação androgênica, hiperqueratinização anormal do ducto pilossebáceo e subsequente colonização bacteriana e inflamação contribuem para a doença (Castillo et al., 2019). Os fatores que influenciam no desenvolvimento da acne são: aumento da produção de sebo, descamação folicular irregular, inflamação e proliferação de Cutibacterium acnes (anteriormente conhecido como Propionibacterium acnes), sendo importante observar que o CBD não é capaz de apenas reduzir a produção de lipídios, mas também de normalizar a lipogênese em um estado de desequilíbrio. (Fox et al., 2016; Baswan et al., 2020).

Com o estudo sobre o papel do CBD em acne, realizado por Olah et al. (2016), foram investigados os efeitos do CBD em sebócitos. O composto inibia a lipogênese, neutralizando agentes indutores de acne, como ácido araquidônico e testosterona. Além disso, o CBD suprimiu a proliferação de sebócitos na ausência de citotoxicidade e expressão prejudicada de TNF- $\alpha$ induzida por agonistas de TLR2 e TLR4. (Martinelli et al., 2021).

\subsection{Etiopatogenia}

A hiperprodução de sebo glandular está relacionada aos hormônios androgênicos, especialmente a testosterona, estimulando o aumento da produção e secreção de sebo. Assim, a produção de sebo se correlaciona diretamente com a gravidade e ocorrência das lesões de acne e, por isso, é um fator importante que deve ser levado em consideração ao lidar com pacientes que sofrem de acne. (Gráfico 1) (Fox et al., 2016). 
Gráfico 1. Fatores que influenciam a Cutibacterium acnes na pele para causar uma infecção oportunista.

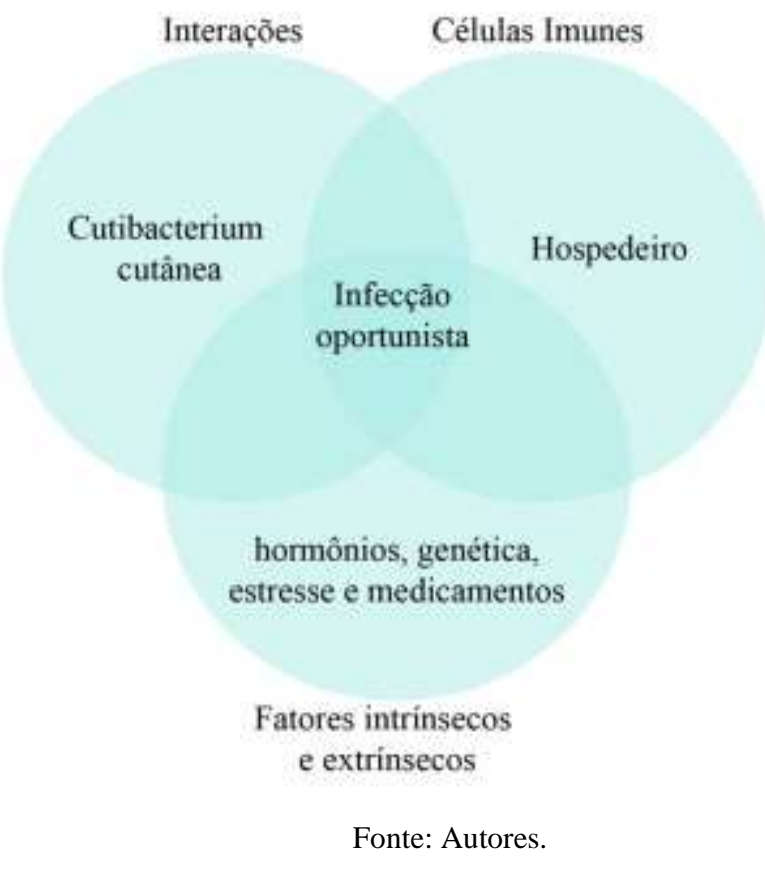

É importante ressaltar que o CBD normalizou a lipogênese "patológica" aprimorada por ácido araquidônico (AA) dos sebócitos em pele humana. Isso sugere que o CBD pode normalizar a produção de lipídios, produzidos de forma excessiva e anormal, induzida por estímulos que contribuem para o desenvolvimento da acne. (Oláh et al., 2016).

\subsection{Colonização bacteriana folicular}

A Cutibacterium acnes é uma bactéria Gram-positiva anaeróbia e microaerofílica, que divide a gordura encontrada na pele em forma de bastonete, representando aproximadamente $90 \%$ do microbioma da pele de adultos saudáveis (Castillo et al., 2019). O desequilíbrio do microbioma cutâneo também pode contribuir para a patogênese da acne. Especificamente, efeitos antimicrobianos conhecidos do CBD também podem ser eficazes no tratamento da acne e no crescimento excessivo de Cutibacterium acnes, produziu um extrato de hexano de semente de cânhamo que exibiu atividade antimicrobiana em $C$. acnes, capaz de reduzir a inflamação e lipogênese em sebócitos em nível molecular e celular. (Baswan et al., 2020).

A microflora presente em um folículo sebáceo normal é qualitativamente semelhante à encontrada em comedões. Isso inclui três grupos coexistentes de bactérias: estafilococos coagulase-negativos, Staphylococcus epidermidis, difteróides anaeróbicos, C. acnes e Propionibacterium granulosum e leveduras lipofílicas, espécies Pityrosporum. (Fox et al., 2016).

\subsection{Inflamação folicular e dérmica subjacente}

O processo inflamatório começa quando C. acnes é detectada pelo sistema imunológico, exibindo efeito altamente inflamatório que pode desencadear a liberação de fatores quimiostáticos, como linfócitos, neutrófilos e macrófagos, podendo causar danos foliculares, ruptura e vazamento de bactérias, ácidos graxos e lipídios para a derme circundante. (Fox et al., 2016).

\subsection{Influências hormonais}

Na puberdade os índices elevados em andrógenos levam a um ambiente mais suscetível ao desenvolvimento de acne a uma mudança na concentração do microbioma para níveis altos de Cutibacterium acnes e Corynebacterium. (Castillo et al., 2019). 


\section{Legislação da Cannabis sativa}

No Brasil, a Resolução da Diretoria Colegiada (RDC) № 327 de 9 de dezembro de 2019 regulamenta os procedimentos para autorização sanitária para fabricação, importação, comercialização, prescrição, monitoramento e a fiscalização de produtos baseados em canabis utilizados para fins medicinais. Segundo o capítulo II da RDC, especificamente no Art. $4^{\circ}$, os produtos derivados da Cannabis sativa devem possuir predominantemente canabidiol (CBD) e não ultrapassando mais do que 0,2\% de tretahidrocanabidiol (THC), porém de acordo com o Art. $5^{\circ}$ os cosméticos, produtos fumígenos ou alimentos à base de Cannabis sativa não são considerados produtos para fins medicinais, não sendo permitidos pela legislação.

Uma comissão especial da câmara dos deputados está analisando o projeto de lei 399/15 com um parecer favorável à legalização do cultivo da canabis no Brasil, exclusivamente para fins medicinais, veterinários, científicos e industriais, mas com algumas restrições. O plantio poderá ser feito somente por pessoas jurídicas, empresas, associações de pacientes ou organizações não governamentais, mas não há previsão para a liberação do cultivo individual.

O cenário internacional já demonstra mudanças em relação a regulamentação da canabis, para fins medicinais, sendo legalizada em 33 estados dos Estados Unidos, Israel, Austrália, Uruguai, Canadá e muitos países europeus. Com a ampliação do uso da canabis medicinal, o estigma e o preconceito devido ao uso recreativo indiscriminado diminuíram, impulsionando o desenvolvimento de novos produtos com fins medicinais que podem ser alternativas para os tratamentos convencionais. (Carliner et al., 2017; Spindle et al., 2019).

\section{Considerações Finais}

O interesse pelas propriedades farmacológicas da Cannabis sativa vem se destacando nos últimos anos, principalmente pelas ações anti-inflamatórias. Os canabinoides são substâncias importantes com significativas ações na pele e evidências, demonstrando que o sistema endocanabinoide e o CBD possuem um perfil de segurança positivo sobre a fisiologia e a patologia cutânea, tornando-se uma alternativa para o tratamento da acne em oposição ao uso da isotretinoína.

Sendo classificada como uma doença crônica devido a sua recorrência e formas de manifestação, por ser uma inflamação, a acne causa irritações e desconfortos na pele, além do incomodo visual que pode influenciar o estado emocional e a autoestima de quem apresenta essa condição dermatológica. Os dermocosméticos com Cannabis sativa em sua composição demonstram eficácia para o tratamento da acne devido a sua significativa ação anti-inflamatória, principalmente pelo fato das glândulas sebáceas possuírem receptores endocanabinoides, os receptores CB1 e CB2, que também contribuem para a homeostase da pele. $\mathrm{O}$ tratamento dá-se pelo efeito supressor da indução das enzimas anti-inflamatórias da Cannabis, reduzindo a secreção de citocinas.

A legislação exige a regulamentação para fabricação, importação, comercialização, prescrição, monitoramento e a fiscalização de produtos baseados em C. sativa utilizados para fins medicinais, assim como existe a necessidade da revisão pelo órgão regulamentador brasileiro (ANVISA) sobre a função de um dermocosmético, possibilitando a inclusão do óleo canabidiol no desenvolvimento de formulações com finalidade antiacne. Apesar do cenário internacional ser promissor e com um grande potencial terapêutico para o CBD em casos de acne, eczema, dermatite e a função de barreira cutânea, são necessários estudos complementares que possam ampliar o conhecimento atual, contribuindo com o desenvolvimento de produtos seguros. Como perspectivas à medida que a burocratização em torno da Cannabis diminui com a sua descriminalização para fins medicinais temos um cenário cada vez mais favorável para inovação de medicamentos e dermocosméticos a base Cannabis que serão uma alternativa aos tratamentos convencionais para diversas patologias e em especial a acne. 


\section{Referências}

Ahmed, W., \& Katz, S. (2016). Therapeutic use of cannabis in inflammatory bowel disease. Gastroenterology \& Hepatology, 12(11), 668-679.

An, D., Peigneur, S., Hendrickx, L. A., \& Tytgat, J. (2020). Targeting cannabinoid receptors: Current status and prospects of natural products. International Journal of Molecular Sciences, 21(14), 5064.

Atalay, S., Jarocka-Karpowicz, I., \& Skrzydlewska, E. (2019). Antioxidative and anti-inflammatory properties of cannabidiol. Antioxidants (Basel, Switzerland), $9(1), 21$.

Aizpurua-Olaizola, O., Soydaner, U., Öztürk, E., Schibano, D., Simsir, Y., Navarro, P., Etxebarria, N., \& Usobiaga, A. (2016). Evolution of the Cannabinoid and Terpene Content during the Growth of Cannabis sativa Plants from Different Chemotypes. Journal of Natural Products, 79(2), 324-331. https://doi.org/10.1021/acs.jnatprod.5b00949

Balant, M., Gras, A., Ruz, M., Vallès, J., Vitales, D., \& Garnatje, T. (2021). Traditional uses of Cannabis: An analysis of the CANNUSE database. Journal of Ethnopharmacology, 279(114362), 114362.

Baswan, S. M., Klosner, A. E., Glynn, K., Rajgopal, A., Malik, K., Yim, S., \& Stern, N. (2020). Therapeutic potential of cannabidiol (CBD) for skin health and disorders. Clinical, Cosmetic and Investigational Dermatology, 13, 927-942.

Bollag, W. B., Aitkens, L., White, J., \& Hyndman, K. A. (2020). Aquaporin-3 in the epidermis: more than skin deep. American Journal of Physiology. Cell Physiology, 318(6), C1144-C1153.

Cannabis medicinal: realidade à espera de regulamentação. (n.d.). Leg.Br. https://www12.senado.leg.br/noticias/infomaterias/2021/07/cannabis-medicinalrealidade-a-espera-de-regulamentacao

Carliner, H., Brown, Q. L., Sarvet, A. L., \& Hasin, D. S. (2017). Cannabis use, attitudes, and legal status in the U.S.: A review. Preventive medicine, 104, 1323. https://doi.org/10.1016/j.ypmed.2017.07.008

Casares, L., García, V., Garrido-Rodríguez, M., Millán, E., Collado, J. A., García-Martín, A., Peñarando, J., Calzado, M. A., de la Vega, L., \& Muñoz, E. (2020). Cannabidiol induces antioxidant pathways in keratinocytes by targeting BACH1. Redox Biology, 28(101321), 101321.

Casiraghi, A., Musazzi, U. M., Centin, G., Franzè, S., \& Minghetti, P. (2020). Topical administration of cannabidiol: Influence of vehicle-related aspects on skin permeation process. Pharmaceuticals (Basel, Switzerland), 13(11), 337.

Castillo, D. E., Nanda, S., \& Keri, J. E. (2019). Propionibacterium (Cutibacterium) acnes bacteriophage therapy in acne: Current evidence and future perspectives. Dermatology and Therapy, 9(1), 19-31.

Caterina, M. J. (2014). TRP channel cannabinoid receptors in skin sensation, homeostasis, and inflammation. ACS Chemical Neuroscience, 5(11), 1107-1116.

Chambers, E. S., \& Vukmanovic-Stejic, M. (2020). Skin barrier immunity and ageing. Immunology, 160(2), 116-125.

Chiurchiù, V., Rapino, C., Talamonti, E., Leuti, A., Lanuti, M., Gueniche, A., Jourdain, R., Breton, L., \& Maccarrone, M. (2016). Anandamide suppresses proinflammatory T cell responses in vitro through type-1 cannabinoid receptor-mediated mTOR inhibition in human keratinocytes. The Journal of Immunology, 197(9), 3545-3553.

Comissão aprova proposta para legalizar no Brasil o cultivo de Cannabis sativa para fins medicinais. (n.d.). Leg.Br. Retrieved October 17, 2021, from https://www.camara.leg.br/noticias/769630-comissao-aprova-proposta-para-legalizar-no-brasil-o-cultivo-de-cannabis-sativa-para-fins-medicinais

Dhadwal, G., \& Kirchhof, M. G. (2018). The risks and benefits of cannabis in the dermatology clinic. Journal of Cutaneous Medicine and Surgery, 22(2), 194199.

Du, Y., Ren, P., Wang, Q., Jiang, S.-K., Zhang, M., Li, J.-Y., Wang, L.-L., \& Guan, D.-W. (2018). Cannabinoid 2 receptor attenuates inflammation during skin wound healing by inhibiting M1 macrophages rather than activating M2 macrophages. Journal of Inflammation (London, England), 15 (1), 25.

Fox, L., Csongradi, C., Aucamp, M., du Plessis, J., \& Gerber, M. (2016). Treatment modalities for acne. Molecules (Basel, Switzerland), $21(8), 1063$.

Graczyk, M., Lewandowska, A. A., \& Dzierżanowski, T. (2021). The therapeutic potential of cannabis in counteracting oxidative stress and inflammation. Molecules (Basel, Switzerland), 26(15), 4551.

Gravitz L. Skin. Nature. 2018 Nov;563(7732):S83. 10.1038/d41586-018-07428-4.

Hargis, A. M., \& Myers, S. (2017). The Integument. In Pathologic Basis of Veterinary Disease (pp. 1009-1146.e1). Elsevier.

Hashim, P. W., Cohen, J. L., Pompei, D. T., \& Goldenberg, G. (2017). Topical cannabinoids in dermatology. Cutis; Cutaneous Medicine for the Practitioner, $100(1), 50-52$.

Heng, A. H. S., \& Chew, F. T. (2020). Systematic review of the epidemiology of acne vulgaris. Scientific Reports, 10(1), 5754.

Hoover, E., Aslam, S., \& Krishnamurthy, K. (2020). Physiology, Sebaceous Glands. In StatPearls. StatPearls Publishing.

Iffland, K., \& Grotenhermen, F. (2017). An update on safety and side effects of cannabidiol: A review of clinical data and relevant animal studies. Cannabis and Cannabinoid Research, 2(1), 139-154.

Imprensa Nacional. (n.d.). Imprensa Nacional. Gov.Br. Retrieved October 17, 2021, from https://www.in.gov.br/en/web/dou/-/resolucao-da-diretoria-colegiadardc-n-327-de-9-de-dezembro-de-2019-232669072 
Isidore, E., Karim, H., \& Ioannou, I. (2021). Extraction of phenolic compounds and terpenes from cannabis sativa L. by-products: From conventional to intensified processes. Antioxidants (Basel, Switzerland), 10(6), 942.

Kupczyk, P., Reich, A., \& Szepietowski, J. C. (2009). Cannabinoid system in the skin - a possible target for future therapies in dermatology. Experimental Dermatology, 18(8), 669-679.

Lewis, M. M., Yang, Y., Wasilewski, E., Clarke, H. A., \& Kotra, L. P. (2017). Chemical Profiling of Medical Cannabis Extracts. ACS Omega, 2(9), 6091-6103. https://doi.org/10.1021/acsomega.7b00996

Lim, M., \& Kirchhof, M. G. (2019). Dermatology-related uses of medical cannabis promoted by dispensaries in Canada, Europe, and the United States. Journal of Cutaneous Medicine and Surgery, 23(2), 178-184.

Lim, X. Y., Tan, T. Y. C., Muhd Rosli, S. H., Sa'at, M. N. F., Sirdar Ali, S., \& Syed Mohamed, A. F. (2021). Cannabis sativa subsp. sativa's pharmacological properties and health effects: A scoping review of current evidence. PloS One, 16(1), e0245471.

Lowe, H., Toyang, N., Steele, B., Bryant, J., \& Ngwa, W. (2021). The Endocannabinoid System: A potential target for the treatment of various diseases. International Journal of Molecular Sciences, 22(17), 9472.

Martinelli, G., Magnavacca, A., Fumagalli, M., Dell'Agli, M., Piazza, S., \& Sangiovanni, E. (2021). Cannabis sativa and Skin Health: Dissecting the Role of Phytocannabinoids. Planta Medica. https://doi.org/10.1055/a-1420-5780

Millar, S. A., Maguire, R. F., Yates, A. S., \& O’Sullivan, S. E. (2020). Towards better delivery of cannabidiol (CBD). Pharmaceuticals (Basel, Switzerland), 13(9), 219.

Nam, G., Jeong, S. K., Park, B. M., Lee, S. H., Kim, H. J., Hong, S.-P., Kim, B., \& Kim, B.-W. (2016). Selective cannabinoid receptor-1 agonists regulate mast cell activation in an oxazolone-induced atopic dermatitis model. Annals of Dermatology, 28(1), 22-29.

Oláh, A., Markovics, A., Szabó-Papp, J., Szabó, P. T., Stott, C., Zouboulis, C. C., \& Bíró, T. (2016). Differential effectiveness of selected non-psychotropic phytocannabinoids on human sebocyte functions implicates their introduction in dry/seborrhoeic skin and acne treatment. Experimental Dermatology, 25(9), $701-707$.

Oláh, A., Tóth, B. I., Borbíró, I., Sugawara, K., Szöllõsi, A. G., Czifra, G., Pál, B., Ambrus, L., Kloepper, J., Camera, E., Ludovici, M., Picardo, M., Voets, T., Zouboulis, C. C., Paus, R., \& Bíró, T. (2014). Cannabidiol exerts sebostatic and antiinflammatory effects on human sebocytes. The Journal of Clinical Investigation, 124(9), 3713-3724.

Osseiran, S., Cruz, J. D., Jeong, S., Wang, H., Fthenakis, C., \& Evans, C. L. (2018). Characterizing stratum corneum structure, barrier function, and chemical content of human skin with coherent Raman scattering imaging. Biomedical Optics Express, 9(12), 6425-6443.

Rippa, A. L., Kalabusheva, E. P., \& Vorotelyak, E. A. (2019). Regeneration of dermis: Scarring and cells involved. Cells (Basel, Switzerland), 8(6), 607.

Scheau, C., Badarau, I. A., Mihai, L.-G., Scheau, A.-E., Costache, D. O., Constantin, C., Calina, D., Caruntu, C., Costache, R. S., \& Caruntu, A. (2020). Cannabinoids in the pathophysiology of skin inflammation. Molecules (Basel, Switzerland), 25(3), 652.

Souza, A. A. F. de, Silva, A. F. M. da, Abreu, L. R. de, Silva, T. F. da, Greco, G., Santos, S. da S., \& Gonzaga, R. V. (2021). Medicinal uses of Cannabis sp. Research, Society and Development, 10(7), e58010716930.

Souza, M. T. D., Silva, M. D. D., \& Carvalho, R. D. (2010). Revisão integrativa: o que é e como fazer. Einstein, 8, 102-106.

Spindle, T. R., Bonn-Miller, M. O., \& Vandrey, R. (2019). Changing landscape of cannabis: novel products, formulations, and methods of administration. Current opinion in psychology, 30, 98-102. https://doi.org/10.1016/j.copsyc.2019.04.002

Tallima, H., \& El Ridi, R. (2018). Arachidonic acid: Physiological roles and potential health benefits - A review. Journal of Advanced Research, 11, $33-41$.

Turcotte, C., Blanchet, M.-R., Laviolette, M., \& Flamand, N. (2016). The CB2 receptor and its role as a regulator of inflammation. Cellular and Molecular Life Sciences: CMLS, 73(23), 4449-4470.

Veniaminova, N. A., Grachtchouk, M., Doane, O. J., Peterson, J. K., Quigley, D. A., Lull, M. V., Pyrozhenko, D. V., Nair, R. R., Patrick, M. T., Balmain, A., Dlugosz, A. A., Tsoi, L. C., \& Wong, S. Y. (2019). Niche-specific factors dynamically regulate sebaceous gland stem cells in the skin. Developmental Cell, 51(3), 326-340.e4.

Yousef, H., Alhajj, M., \& Sharma, S. (2021). Anatomy, skin (integument), epidermis. In StatPearls. StatPearls Publishing. 